\title{
Talleres artísticos con mujeres pimas y jóvenes grafiteros de Hermosillo
}

\author{
Marisela Moreno Cano*
}

Hablaré de mi experiencia y de cómo surge la idea al inicio de un proyecto, integrando los puntos de atención y observación, producto de esas experiencias, porque son estos mismos los que permiten a un artista desarrollarse y llevar a cabo futuros proyectos.

Era el año 1999, yo me encontraba aquí en Hermosillo cuando me llamó la Asociación Lutisuc dedicada a trabajar con pueblos indígenas de Sonora, su presidenta y creadora, la señora Inmaculada Puente de Corella, sabía de mis trabajos con niños y jóvenes en distintas ciudades de Sonora, brindando talleres de pintura. El proyecto trataba de El rescate de artesanías, y su interés era trabajar con el pueblo pima.

En aquellos años, el rezago de los pueblos indígenas era aún mayor, y hablando específicamente de los pimas, créanlo o no, la mayoría de la población ni siquiera sabía que existían.

Cuando me ofreció ese trabajo, yo no imaginaba ni los riesgos ni el gran reto que esto significaba; y fue mejor no saberlo porque mi respuesta fue un sí desde el primer momento.

Lo primero que hice fue ir a la biblioteca del Museo de la Universidad de Sonora, a buscar libros que hablaran acerca de sus tradiciones; yo no quería llegar en blanco a sus tierras, me daba vergüenza.

En dicha biblioteca, solo un libro llamó mi atención y era uno que narraba cómo un español había llegado a tierras pimas y lo que había visto. Ese libro solo mostraba un dibujo de una máscara, nada más.

\footnotetext{
* Licenciada en Artes Gráficas y Diseño. Master en Arte Actual. Desde 1992 ha realizado exposiciones individuales en diferentes ciudades de México y Estados Unidos. Actualmente se desempeña como directora del Instituto Municipal de Fomento a la Cultura y las Artes de Nogales, Sonora.
}

No había mucho tiempo para investigar, así que me lancé a lo desconocido con lo que yo trabajaba aquí, lo normal: cartulinas, pintura vinílica, los colores básicos, carboncillo, lápices y pinceles.
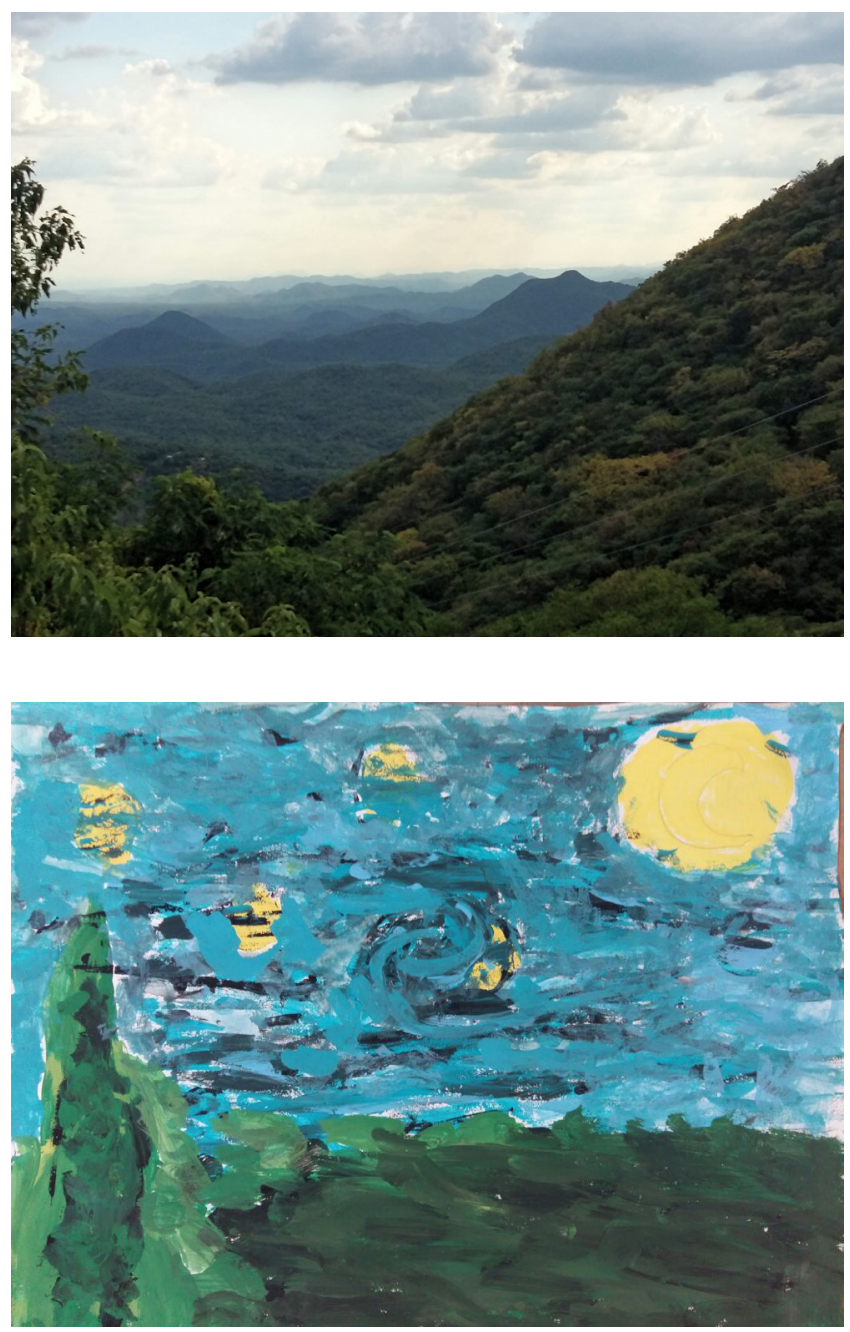

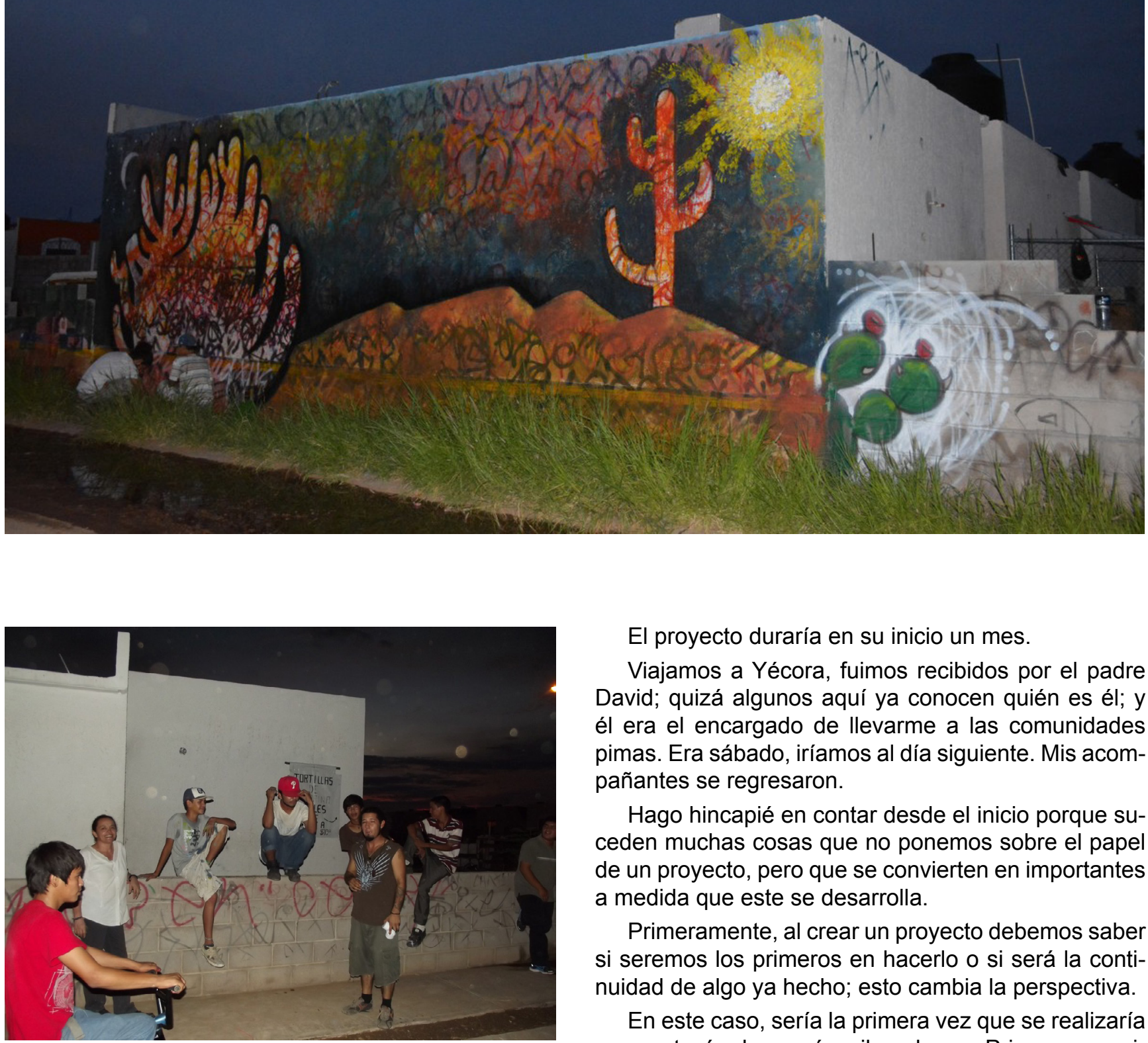

El proyecto duraría en su inicio un mes.

Viajamos a Yécora, fuimos recibidos por el padre David; quizá algunos aquí ya conocen quién es él; y él era el encargado de llevarme a las comunidades pimas. Era sábado, iríamos al día siguiente. Mis acompañantes se regresaron.

Hago hincapié en contar desde el inicio porque suceden muchas cosas que no ponemos sobre el papel de un proyecto, pero que se convierten en importantes a medida que este se desarrolla.

Primeramente, al crear un proyecto debemos saber si seremos los primeros en hacerlo o si será la continuidad de algo ya hecho; esto cambia la perspectiva.

En este caso, sería la primera vez que se realizaría y yo no tenía claro qué se iba a lograr. Primero necesitaba que me tuvieran confianza y me abrieran sus co-

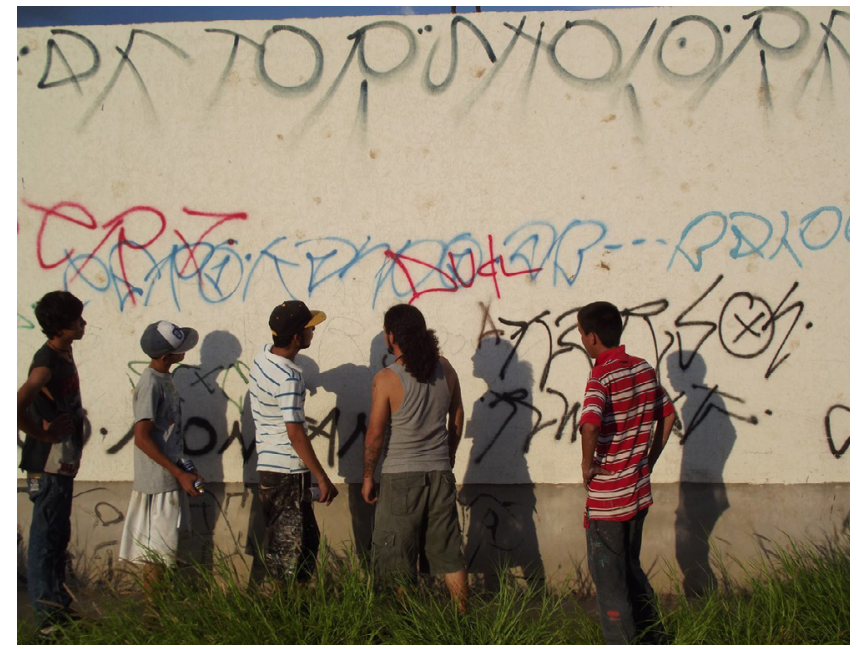
razones. Tampoco sabía cómo vivían, ni qué comían. Podrán imaginar lo aventurado que era para mí.

El día domingo llegó y dio inicio mi aventura, el paisaje era bellísimo, fuimos en una troca de redilas de esas para cargar ganado, el padre David manejaba. Llegamos a la primera comunidad, la de Los Pilares, con muy pocas familias habitando; ahí serían mis primeras clases. Tenían un aula de escuela, yo viviría en un cuarto enseguida de la casa de la familia.

Ese día el padre invitó a las familias a seguir nuestro paseo, río adentro; yo trataba de memorizar el entorno, no les entendía nada, pues solo hablaban en su lengua.

Llegamos a una parte ancha del afluente del río y ahí me di cuenta que era como un bautizo para mí; de ese momento dependía si me aceptaban y si yo me 


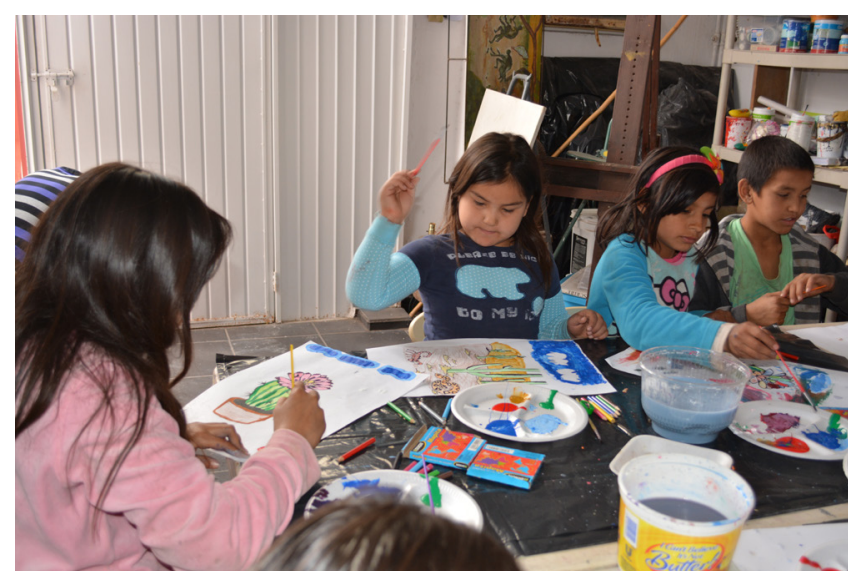

adaptaba, el padre me dejaba a mí sola conviviendo con ellos.

De regreso anocheció, me quedé en Los Pilares, en el que sería mi cuarto, ya los niños me rodeaban y querían saber qué era eso de pintar.

Por las noches yo escribía todo lo que observaba, lo hacía con el fin de adaptarme a ellos y adaptar mis técnicas de enseñanza de pintura, de acuerdo con sus gustos y conocimientos. Yo no llevaba nada ya dibujado, ni libros ni revistas, nunca quise interrumpir su entorno y sabiduría. Pero al mismo tiempo luchaba porque ellos me contaran y lo expresaran a través de la pintura y el dibujo.

Tuve en esa comunidad trece alumnas y alumnos en edades de cinco a catorce años.

El dueño de la casa me enseñó un arco que él hacía para cazar venados y fue a él a quien le enseñé la fotografía del dibujo de la máscara. Logramos hacer algunas, pero no podía evitar que al darme yo la vuelta, le incrustaran elementos de las máscaras pascolas yaquis que ellos ya conocían.

Con los niños realizaba pinturas basadas en sus cuentos autóctonos, en su naturaleza y en cómo eran sus familias. Era encantador ver sus caritas de asombro cuando yo abría las latas de pintura.

Después llevé manta, ya yo pensaba en cómo hacer algo que fuera productivo y lo pudieran vender, así que cortaba la manta para hacer mantelitos de mesa y murales de hasta dos por dos metros.

Mientras yo daba clase a los niños, algunas mujeres iban a observar. Empecé a pensar qué actividad podrían hacer ellas; y una noche, escribiendo, recordé que en la comunidad de El Kipor, había visto a una mujer bordar y no me había gustado el dibujo del bordado que ella había sacado de una revista de Corín Tellado, que llevaron unas monjas. Entonces empecé a idear los diseños para bordar, basándome en las pinturas rupestres que se encuentran cerca de allí, ha- ciendo composiciones con significados y así fue como pedí material para bordar; les dibujé sus diseños en manta, después se invitó a otras maestras para ayudarles a perfeccionar la técnica; luego con los años, Lutisuc les compró máquinas de coser y habilitó una casa comunitaria donde se reúnen y organizan todo su material para su venta, de tal forma que resultó ser una actividad productiva que les ha permitido obtener ingresos y trabajo.

Los talleres se brindaron en las comunidades de Los Pilares, Juan Diego y El Kipor. Actualmente, sus bordados se encuentran en diversos artículos y ropa elaborada por ellas mismas.

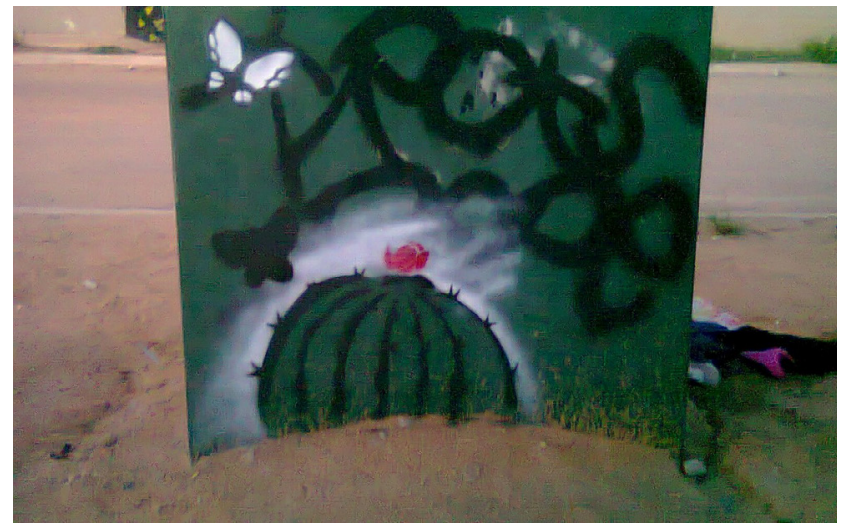

\section{Los cuatro puntos culturales}

Proyecto iniciado con el objetivo de pintar murales con jóvenes grafiteros en Hermosillo, en el año 2016, con productos finales realizados en la colonia La ChoIla y en Magdalena Sonora.

Es conocido el mundo del grafiti como un mundo que molesta, que estorba, que mancha, ensucia... El grafiti es conocido por todos y en su gran mayoría es realizado por grupos de jóvenes problemáticos, rebeldes, drogadictos, alcohólicos, etc.

Son trazos que solo el que los pinta los entiende, la mayor parte de las veces; son un grito pintado, lo llamaría yo. Sabemos que el grafitero lo hace para marcar territorio y obtener reconocimiento de sus compañeros, pero para la población en general, carece de sentido.

Mi proyecto lo llevé al Instituto Municipal de Cultura y ellos encontraron el momento y la colonia donde iniciar.

Fue en la colonia La Cholla, conocida por sus graves conflictos de inseguridad, delincuencia y drogadicción. Mi proyecto se uniría a una serie de actividades promovidas por el ayuntamiento y la construcción de un parque. 

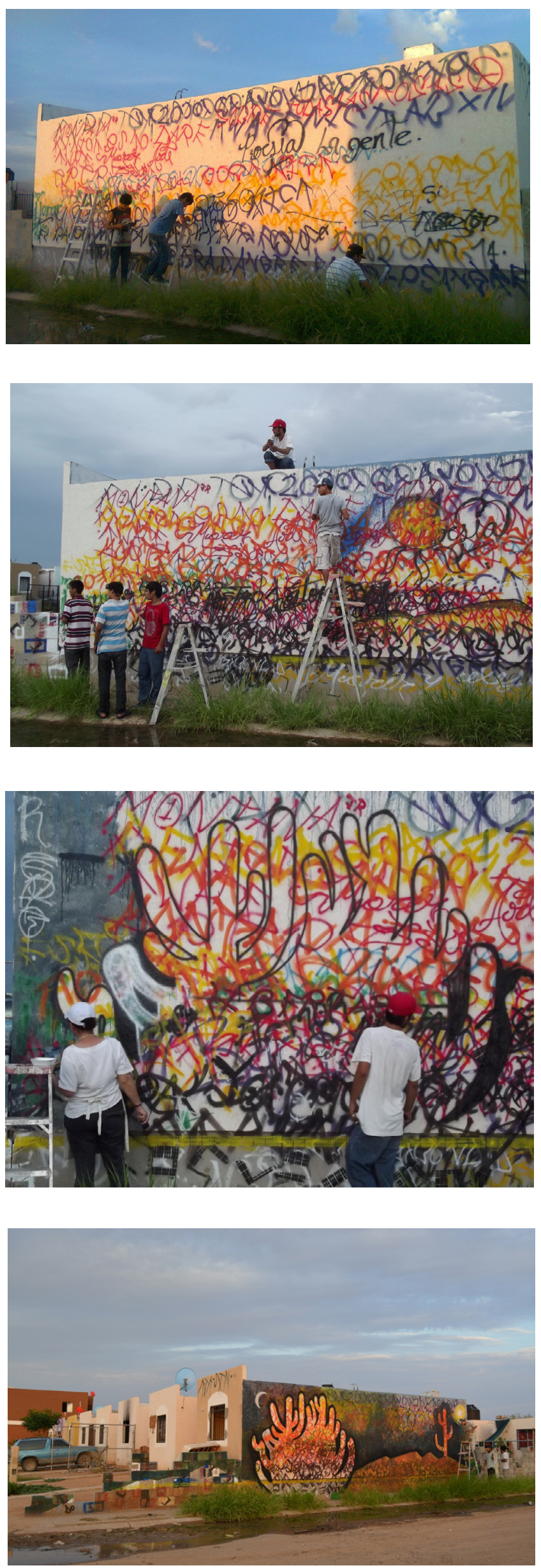

Mi proyecto consistió de dos etapas, la primera era la de capacitar a los jóvenes enseñando algunas técnicas para pintar murales; y la segunda, consistía ya en pintar los murales.

Pero ¿cómo empezar?, ¿cómo despertar en ellos la confianza? Por supuesto, hubo algunas personas que me preguntaron, ¿y no te da miedo?

Lo primero que hice fue reunir un equipo y le hablé a dos artistas que ya habían trabajado el grafiti; por fortuna ellos aceptaron. Yo solamente había hecho una visita a la colonia tratando de buscar pistas para introducirme y había encontrado una reunión de señoras en una casa; me bajé del carro a platicar con ellas y escuchar sus necesidades; les dije lo que quería hacer y lo tomaron muy bien, pero en primera instancia pedían leche de Diconsa.

La siguiente visita la hice con mi equipo, nos instalamos en un parque decididos a empezar con las clases. La voz corrió y fueron llegando jóvenes, mujeres y hombres desde catorce años hasta dieciocho o veinte.

Iniciaron casi veinte y fueron quedando seis, que por supuesto, esos eran los grafiteros.

Uno de los objetivos de mi proyecto es no borrar sus grafitis, sino transformarlos, compartir la técnica de ellos con la técnica tradicional del mural.

La confianza pronto llegó y yo seleccioné una barda de una casa que estaba completamente grafiteada por ellos.

La propuesta fue no borrar; trabajaríamos sobre lo ya pintado, utilizando transparencias con distintas técnicas. Yo quería que ellos sintieran la libertad y transformar poco a poco sus grafitis.

Les llevamos algunos libros, unos de poesía, y los incitamos a seleccionar frases de los poemas y escribirlas, grafitearlas en el muro y que escribieran lo que ellos quisieran.

Por supuesto, era extraño para ellos estar pintando sin interrupción de la policía o algún vecino.

Pasaba la gente de la colonia por ahí con mucha curiosidad, a medida que el trabajo se estaba terminando les gustaba y me decían: "iyo les presto mi barda para pintarla!"; y también me decían: "iqué bueno que puso a trabajar a estos... para que dejen de hacer daño...!".

Prometimos volver... ya no volvimos. El proyecto no continuó en otras colonias por falta de recursos. 